\title{
Rarely Encountered, Seldom Considered: Posterior Tibial Nerve Schwannoma Mimicking Lumbar Radiculopathy
}

Sir,

A 63-year-old female presented with progressively increasing pain in the right leg and foot along the S1 dermatome and dysesthesias for 3 years duration. There was no history of back pain, and the leg pain was unrelated to posture and activity and even occurred at rest. A magnetic resonance imaging (MRI) of the spine was noncontributory, and she was treated with medications, physiotherapy and even an epidural block without any relief. Six months ago, she noted a swelling in the posterolateral aspect of her right lower limb, palpation of which was painful. An MRI of the right leg showed an enhancing tumor probably arising from posterior tibial nerve deep to the tendoachilles and superficial to the deep flexors in the posterior compartment of the leg [Figure 1]. On examination, the swelling was ill-defined and tender. There were no motor or sensory deficits.

Microscopic intracapsular excision of the lesion was done under spinal anesthesia. The tumor was vascular, pinkish, gritty in consistency, and nonsuckable. It was adherent to the posterior tibial nerve from which it was dissected off after initial intratumoral decompression. The integrity of the nerve was intact after tumor removal [Figure 2]. The lesion was reported as a schwannoma on histopathology [Figure 3]. There were no postoperative neurological deficits, and the patient was symptom-free after the surgery.

Schwannomas are the most common tumors arising from peripheral nerves..$^{[1,2]}$ Usually, they are solitary lesions with no gender predilection. ${ }^{[3]}$ The posterior tibial nerve is the most commonly affected nerve in the lower $\operatorname{limb}^{[2]}$ as was found in our case too. They may present either as an asymptomatic lump or with neuropathic pain which is usually mistaken to be due to lumbar radiculopathy or entrapment neuropathy. ${ }^{[1]}$ As in our case, previous reports in literature also emphasize that the diagnosis is usually delayed - often by several years. ${ }^{[1,4]}$ Nawabi and Sinisi have described 25 cases of tibial nerve schwannoma where the mean duration from symptom onset to diagnosis was 86.5 months. All their patients presented with neuropathic pain had a positive Tinel's sign and $48 \%$ had a palpable swelling as well. ${ }^{[1]}$ The lesion may be mistaken for a ganglion, fibroma, or myxoma. ${ }^{[2]}$ MRI is the investigation of choice to both confirm the diagnosis ${ }^{[1]}$ and see the tumor's relationship to neighboring structures.

Though unlike neurofibromas, complete removal of schwannomas is possible without damage to the nerve, in large lesions uninvolved fibers may be splayed over the nerve, and extracapsular excision may cause damage of such fascicles. ${ }^{[4]}$ In this patient, we performed an intracapsular excision after making a longitudinal incision over the tumor in the axis of the nerve to minimize neural injury.

To conclude, peripheral nerve tumors must be considered in patients who have unresponsive leg pain mimicking lumbar radiculopathy but with normal spinal imaging. Careful limb examination for the presence of a lump along the course of the nerve and presence of 


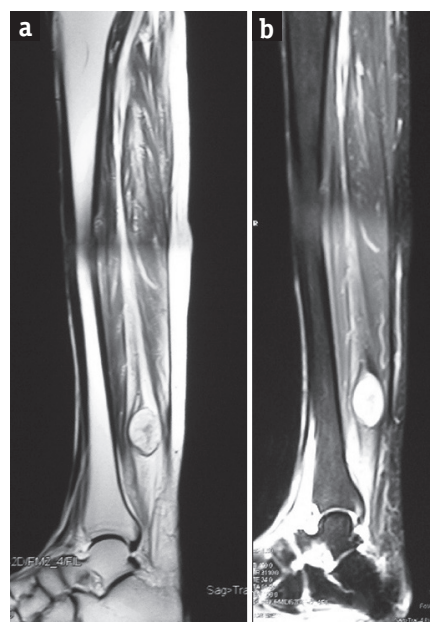

Figure 1: Sagittal magnetic resonance imaging (a) T2 sequence and (b) postcontract fat saturated T1 sequence showing a well-defined uniformly enhancing mass in the posterior compartment of the leg deep to the tendo-achilles and superficial to the long flexors of the ankle and toes

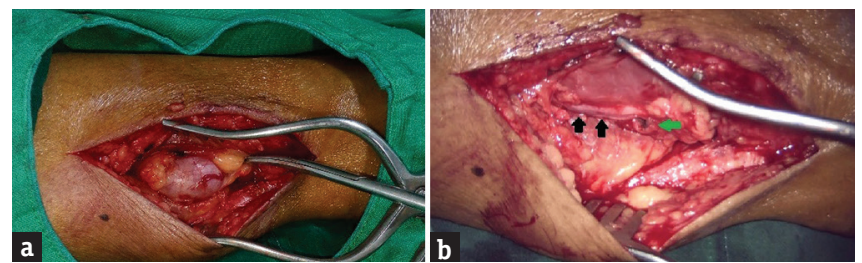

Figure 2: Intraoperative photograph showing (a) a well-defined pinkish tumor being delivered through an approach between the peroneal and posterior compartments and (b) intact posterior tibial nerve (black arrows) after removal of the tumor. The place of attachment to the nerve is shown by green arrow

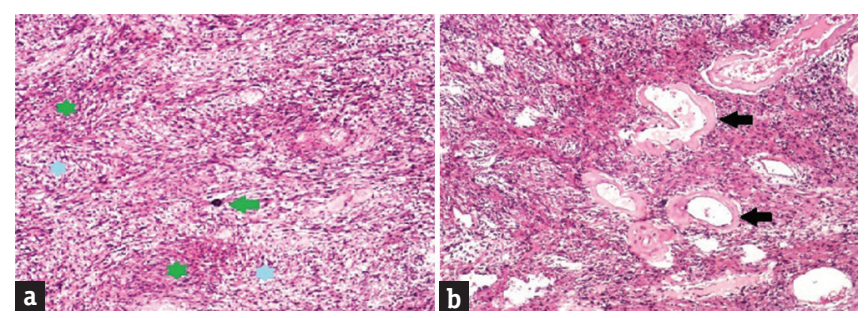

Figure 3: Histopathological slides showing (a) alternate areas of hypercellularity (green stars) and hypocellularity (blue stars) representing Antoni A and Antoni B areas respectively with calcification (green arrow) in the tumor and (b) thick walled hyalinized blood vessels (black arrows) in a background of short interlacing fascicles of spindle cells with scattered Verocay bodies

Tinels' sign should alert the physician to this possibility. Surgical excision provides relief even in patients with longstanding pain, and finally, intracapsular excision of the lesion must be considered if nerve fascicles are splayed over the tumor and cannot be separated easily.

\section{Declaration of patient consent}

The authors certify that they have obtained all appropriate patient consent forms. In the form the patient(s) has/have given his/her/their consent for his/ her/their images and other clinical information to be reported in the journal. The patients understand that their names and initials will not be published and due efforts will be made to conceal their identity, but anonymity cannot be guaranteed.

\section{Financial support and sponsorship}

Nil.

\section{Conflicts of interest}

There are no conflicts of interest.

\section{Dhruv Kumar Agarwal, Eswararao Thamatapu,} Sugat Sanyal, Prasad Krishnan

Department of Neurosurgery, National Neurosciences Centre, ${ }^{1}$ Department of Pathology, Peerless Hospital and B K Roy Research Center, Kolkata, West Bengal, India

Address for correspondence: Dr. Prasad Krishnan, National Neurosciences Centre, Peerless Hospital Campus, $2^{\text {nd }}$ Floor, 360 Pancha Sayar, Kolkata - 700094 , West Bengal, India.

E-mail: prasad.krishnan@rediffmail.com

\section{REFERENCES}

1. Nawabi DH, Sinisi M. Schwannoma of the posterior tibial nerve: The problem of delay in diagnosis. J Bone Joint Surg Br 2007;89:814-6.

2. Kim SM, Seo SW, Lee JY, Sung KS. Surgical outcome of schwannomas arising from major peripheral nerves in the lower limb. Int Orthop 2012;36:1721-5.

3. Rhanim A, El Zanati R, Mahfoud M, Berrada MS, El Yaacoubi M. A rare cause of chronic sciatic pain: Schwannoma of the sciatic nerve. J Clin Orthop Trauma 2013;4:89-92.

4. Ghaly RF. A posterior tibial nerve neurilemoma unrecognized for 10 years: Case report. Neurosurgery 2001;48:668-72.

This is an open access article distributed under the terms of the Creative Commons Attribution-NonCommercial-ShareAlike 3.0 License, which allows others to remix, tweak, and build upon the work non-commercially, as long as the author is credited and the new creations are licensed under the identical terms.

\begin{tabular}{|c|c|}
\hline \multicolumn{2}{|c|}{ Access this article online } \\
\hline $\begin{array}{l}\text { Quick Response Code: } \\
\text { (a) }\end{array}$ & $\begin{array}{l}\text { Website: } \\
\text { www.ruralneuropractice.com }\end{array}$ \\
\hline arpipip & $\begin{array}{l}\text { DOI: } \\
\text { 10.4103/jnrp.jnrp_359_17 }\end{array}$ \\
\hline
\end{tabular}

How to cite this article: Agarwal DK, Thamatapu E, Sanyal S, Krishnan P. Rarely encountered, seldom considered: Posterior tibial nerve schwannoma mimicking lumbar radiculopathy. J Neurosci Rural Pract 2018;9:173-4.

(C) 2018 Journal of Neurosciences in Rural Practice | Published by Wolters Kluwer - Medknow 